\title{
Ebstein's anomaly-How to correct severe anatomical forms of the defect in adults
}

\author{
Patrick Perier ${ }^{1}$, Jacek Pajak ${ }^{2}$, Szymon Pawlak ${ }^{3}$, Marian Zembala ${ }^{3}$ \\ ${ }^{1}$ Herz und Gefäß Klinik, Bad Neustadt/Saale, Germany; ${ }^{2}$ Department of Children's Cardiology, School of Medicine, Katowice, Poland; ${ }^{3}$ Department \\ of Cardiac Surgery and Transplantology in Zabrze, Silesian Medical University, Poland \\ Correspondence to: Patrick Perier, MD. Herz und Gefäss Klinik, Salzburger Leite 1, 97616 Bad Neustadt/Saale, Germany. \\ Email: pperier@club-internet.fr.
}

Submitted Mar 15, 2017. Accepted for publication Mar 27, 2017.

doi: $10.21037 /$ acs.2017.05.13

View this article at: http://dx.doi.org/10.21037/acs.2017.05.13

\section{Clinical vignette}

We present the case of a 43-year-old female with a severe tricuspid regurgitation due to an Ebstein Anomaly. She was in New York Association Functional Class II, and was still in sinus rhythm despite a hugely dilated right atrium. The preoperative workup included a transthoracic and transesophageal echocardiography which showed a typical aspect of Ebstein anomaly with a $1.5 \mathrm{~cm}$ apical displacement of the septal leaflet, dilatation the right atrium and of the right ventricle whose function was decreased. A cardiac catheterization confirmed that the coronary arteries were free of stenotic lesions.

The indication to operate the patient was based on the severity of the tricuspid regurgitation, and the symptoms.

\section{Surgical technique}

\section{Principles}

Ebstein anomaly is a rare congenital malformation of the tricuspid valve and right ventricle that is characterized by a spectrum of several features including (I) adherence of the tricuspid leaflets to the underlying myocardium (failure of delamination); (II) apical displacement of the functional annulus (septal>posterior>anterior); (III) dilatation of the "atrialized portion of the right ventricle; (IV) redundancy, fenestrations and tethering of the anterior leaflet; and (V) dilatation of the right atrioventricular junction (true tricuspid annulus). Due to the varying degree of leaflet delamination failure, the spectrum of severity is variable. Carpentier's classification (1) describing four grades of
Ebstein anomaly depending of the severity of the lesions reflects the complexity of the disease and explains the surgical challenge.

\section{Position}

The operation is performed through median sternotomy using cardiopulmonary bypass, aortic and bicaval cannulation with cross clamping and crystalloid Bretschneider cardioplegia. After the longitudinal right atrium incision, the tricuspid valve is analyzed. The anterior leaflet is detached from the annulus. This should be carried out as much as possible towards the posterior leaflet, until the adhesion to the wall of the right ventricle is so thick that it becomes impossible. Both leaflets are freed from all muscular bands that attach them to the right ventricular wall. This permits the exposition of the papillary muscles, which are dissected and liberated. It is necessary to carry this out to as great an extent as possible to avoid any restriction of the motion of the free edge of the anterior leaflet afterwards. Obliterated interchordal spaces are fenestrated to allow a proper flow in the right ventricular inflow. This step of the operation may be time consuming, but is crucial.

Annular sutures are then placed through the anatomical annulus. The antero-posterior leaflet is then reattached to the true anatomic annulus, with a certain degree of clockwise rotation. Care should be taken not to exaggerate the rotation to avoid any tension and restriction of the subvalvular apparatus.

The atrialized portion of the right ventricle is eventually 
plicated from the apex to the tricuspid annulus, which allows a reduction of the tricuspid annulus at the same time. It is important to control the distance from the plicated wall to the right coronary artery and its branches.

Despite the septal leaflet being hypoplastic and downwardly displaced, it is always possible to isolate a stump of septal leaflet close to the antero-septal commissure.

In case of lack of tissue between the "stump" of the septal leaflet and the remaining posterior leaflet, a piece of autologous pericardium tanned in Glutaraldehyde is tailored to cover the gap, and fashioned to create a new septal leaflet. The piece of pericardium is sutured on one end to the remnant of the septal leaflet with Prolene 5-0, and the other end to the remaining posterior leaflet. One side of the piece of pericardium is sutured with Prolene 5-0 to the true annulus. The free edge of the pericardial leaflet is suspended with one or two set of artificial chordae that are anchored on the interventricular septum. The artificial chordae are tied at the end of the operation, after implantation of the ring, taking advantage of the saline test.

The last step of the operation is the implantation of a tricuspid ring whose role is to remodel and to stabilize the tricuspid valve. The valve is tested by injecting saline into the right ventricle, the line of closure was favorable and there was no residual regurgitation.

\section{Completion}

The weaning from bypass was performed and TOE confirmed a satisfactory tricuspid valve repair with a long surface of coaptation and no tricuspid regurgitation. Decannulation and hemostasis was completed and the patient was transferred to the ICU in a stable condition. The patient was discharged from the hospital on day 9 postoperatively.

\section{Comments}

Ebstein anomaly poses a surgical challenge, because of the variety of the disease and frequent lack of valvular tissue. Most repair techniques address the abnormal tricuspid valve in a manner that focuses on the concept of monocusp repair. Carpentier's approach (1) focuses on mobilization (surgical delamination) of the anterior leaflet with annular reattachment resulting in an anterior leaflet monocusp repair. In $2004 \mathrm{Wu}$ published a new approach using a patch of autologous pericardium to replace a hypoplastic septal leaflet (2).The Brazilian experience (cone operation) is an extension of the Carpentier's technique (3). The difference was a surgical delamination of all available leaflet tissue, and a clockwise rotation of this complex to be sutured to the septal border of the anterior leaflet. The "cone" approach has been refined by the Mayo Clinic group (4); however, in severe anatomical forms of Ebstein anomaly, septal and posterior leaflet are often absent, and a repair is either impossible or is associated with a poor result. The technique presented here is a two-cusp technique, using the native delaminated tricuspid valve, as an anterior leaflet, and creating with autologous pericardium a septal and posterior component, the free edge of which is suspended with artificial chordae.

Twenty-three patients (mean age 25 years old) have been operated on for Ebstein anomaly. A tricuspid valve repair could be performed for all of them. In four patients a monocusp approach was carried out in the beginning of our experience, and in 19 patients a two-cusps technique was applied-12 directly and in seven patients with the use of a pericardial patch. There has been no operative mortality and no reoperation. At discharge, in $74 \%$ patients there was no or grade I tricuspid regurgitation. All patients with a monocusp approach had a persistent tricuspid regurgitation grade 2 or more.

In conclusion, the two cusp approach allows a satisfactory repair of the tricuspid valve with Ebstein anomaly. In case of a severe anatomical form of the disease, the use of a tanned autologous pericardial valve as a substitute to the hypoplastic septal and posterior leaflets expands the technical possibilities of repairing the tricuspid valve.

\section{Acknowledgements}

None.

\section{Footnote}

Conflicts of Interest: The authors have no conflicts of interest to declare.

\section{References}

1. Carpentier A, Chauvaud S, Mace L, et al. A new reconstructive operation for Ebstein's anomaly of the tricuspid valve. J Thorac Cardiovasc Surg 1988;96:92-101.

2. Wu Q, Huang Z. A new procedure for Ebstein's anomaly. Ann Thorac Surg 2004;77:470-6; discussion 476.

3. da Silva JP, Baumgratz JF, da Fonseca L, et al. The cone 
reconstruction of the tricuspid valve in Ebstein's anomaly. The operation: early and midterm results. J Thorac Cardiovasc Surg 2007;133:215-23.

4. Dearani JA, Said SM, O'Leary PW, et al. Anatomic

Cite this article as: Perier P, Pajak J, Pawlak S, Zembala M. Ebstein's anomaly-How to correct severe anatomical forms of the defect in adults. Ann Cardiothorac Surg 2017;6(3):287-289. doi: $10.21037 /$ acs.2017.05.13
Repair of Ebstein's Malformation: Lessons Learned With Cone Reconstruction. Ann Thorac Surg 2013;95:220-6; discussion 226-8. 